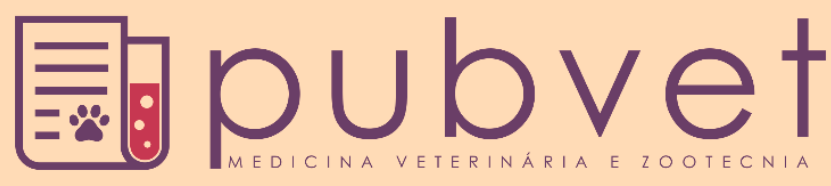

https://doi.org/10.31533/pubvet.v15n11a958.1-7

\title{
Hermafroditismo em bovino: Relato de caso
}

\author{
Marintia de Almeida ${ }^{1} \theta$, Guilherme Furini Cornelli ${ }^{1} \bullet$, Juscivete Fátima Fávero ${ }^{2 *} \bullet$, Willian \\ Gabriel Baldo $^{1 \bullet}$, Nathalia Laurini Zardo ${ }^{1 \oplus}$ \\ ${ }^{I}$ Acadêmico(a) da Universidade Comunitária da Região de Chapecó-Unochapecó. Departamento de Medicina Veterinária. Chapecó- SC, Brasil. \\ ${ }^{2}$ Professora da Universidade Comunitária da Região de Chapecó-Unochapecó. Departamento de Medicina Veterinária, Chapecó- SC, Brasil. \\ *Autor para correspondência, E-mail: juscivete@unochapeco.edu.br
}

Resumo. O termo Intersexualidade inclui as anomalias congênitas do sistema genital em que o paciente apresenta características sexuais ambíguas simultaneamente. São caracterizadas na forma de hermafroditismo verdadeiro, pseudo-hermafroditismo (feminino ou masculino) e o freemartinismo, sendo este o mais recorrente em bovinos. As alterações acontecem durante o desenvolvimento embrionário do aparelho reprodutor e na diferenciação sexual, sendo sua etiologia relacionada a fatores genéticos e ambientais. São diagnosticadas pelos sinais clínicos, exames complementares e avaliações cromossômicas. A similaridade entre as formas da anomalia, requerem atenção para o correto diagnóstico da anormalidade e escolha de tratamento. O objetivo deste trabalho foi relatar um caso de hermafroditismo verdadeiro em um bovino de parto não gemelar, destacando as alterações evidenciadas no exame clínico físico e no exame complementar ultrassonográfico.

Palavras-chave: Anomalia, bovino, hermafroditismo, intersexualidade

\section{Hermaphroditism in a bovine: Case report}

\begin{abstract}
The term Intersexuality includes congenital anomalies of the genital system in which the patient has ambiguous sexual characteristics simultaneously. They are characterized in the form of true hermaphroditism, pseudohermaphroditism (female or male) and freemartinism, which is the most recurrent in cattle. The changes happen during the embryonic development of the reproductive system and in sexual differentiation, its etiology being related to genetic and environmental factors. They are diagnosed by clinical signs, complementary exams and chromosomal evaluations. The similarity between the forms of the anomaly, require attention for the correct diagnosis of the abnormality and choice of treatment. The objective of this study was to report a case of true hermaphroditism in a non-twin calving calf, highlighting the changes evidenced in the physical clinical examination and in the complementary ultrasound examination.
\end{abstract}

Keywords: Anomaly, bovine, hermaphrodism, intersexuality

\section{Hermafroditismo en bovino: Reporte de caso}

Resumen. El término Intersexualidad incluye anomalías congénitas del sistema genital en las que el paciente tiene características sexuales ambiguas simultáneamente. Se caracterizan en forma de verdadero hermafroditismo, pseudohermafroditismo (femenino o masculino) y freemartinismo, que es el más recurrente en el ganado. Los cambios ocurren durante el desarrollo embrionario del sistema reproductivo y en la diferenciación sexual, estando su etiología relacionada con factores genéticos y ambientales. Se diagnostican mediante signos clínicos, exámenes complementarios y evaluaciones cromosómicas. La similitud entre las formas de la anomalía requiere atención para el diagnóstico correcto de 
la anomalía y la elección del tratamiento. El objetivo de este estudio fue reportar un caso de hermafroditismo verdadero en un ternero no gemelo, destacando los cambios evidenciados en la exploración física clínica y en la ecografía complementaria.

Palabras clave: Anomalía, bovino, hermafroditismo, intersexualidad

\section{Introdução}

Anomalias na diferenciação sexual são descritas em múltiplas espécies incluindo bovinos, equinos, ovinos, suínos, cães e humanos (Payan-Carreira et al., 2008). Acontecem tanto no desenvolvimento fetal quanto embrionário, ocorrendo na fase sexo cromossômica com alterações numéricas, sexo gonadal e sexo fenotípico resultando em anomalias no desenvolvimento da genitália (Almeida, 1999; Campbell, 2004). Na fase sexo cromossômica o oócito $X$ é fertilizado por um espermatozoide que carrega $o$ cromossomo X ou Y (Zenteno-Ruiz et al., 2001). Em seguida, na fase sexo gonadal o gene SRY, localizado no cromossomo $\mathrm{Y}$, vai ser responsável pela diferenciação da gônada masculina. Se o indivíduo é do sexo genético XX e não possui o gene SRY, a gônada se diferencia em ovário. Na fase sexo fenotípico se desenvolve de forma ativa no macho, sendo estimulado pela testosterona produzida pelas gônadas diferenciadas (Grunert et al., 2005; Nascimento \& Santos, 2000). Se os hormônios masculinos estão ausentes ou os tecidos não respondem a eles, a tendência passiva é de diferenciação em genitália externa feminina. A determinação natural é que qualquer feto desenvolva uma genitália externa e conformação corporal feminina, quando a ausência dos efeitos masculinizantes dos andrógenos (Howden, 2004). A intersexualidade por sua vez, faz com que o mesmo indivíduo apresente características marcantes dos dois sexos (Grunert et al., 2005; Nascimento \& Santos, 2000).

Alterações no desenvolvimento do aparelho reprodutor ocorrem durante a vida embrionária, decorrentes de malformações nas estruturas primitivas do aparelho reprodutor, as quais se desenvolvem ou sofrem regressão e por doenças estruturais que resultam em erros durante a organogênese e deformações na estrutura orgânica após diferenciação do embrião. A anomalia, se apresenta em três formas, sendo, Freemartinismo, Hermafroditismo verdadeiro e Pseudo- Hermafroditismo. Nos bovinos a apresentação intersexual mais comum é o freemartinismo, que estão relatados principalmente em gestações gemelares heterossexuais e menos encontrada em outras espécies, como ovinos, caprinos, suínos e equinos (Padula, 2005). Nos animais de produção a anomalia acarreta problemas econômicos, pois o indivíduo acometido pela síndrome desenvolve principalmente infertilidade. Predisposições raciais estão associada à etiologia genética, por isso, métodos de seleção são utilizados nos rebanhos e tem se mostrado eficaz na diminuição da ocorrência da anomalia (Basrur \& Basrur, 2004; Basrur \& Stranzinger, 2008). Nos animais domésticos a prevalência de malformações pode estar associada à consanguinidade e em algumas espécies, também foi relatada devido à exposição desses indivíduos a contaminantes químicos ambientais (Fernández et al., 2007).

Em bovinos o diagnóstico é feito pelo exame clínico de palpação retal, exame complementar ultrassonográfico e vaginoscopia. Além métodos para diagnóstico precoce, como a citogenética, que possibilita identificar e eliminar a reprodução dos animais acometidos, evitando maiores prejuízos ao criador. A técnica de FISH (Hibridação Fluorescente in situ) que fundamenta- se no uso de uma sequência de bases (sonda) complementar ao DNA que se pretende estudar (Chauffaille, 2005), marcadas com fluorocromos, permitindo identificar a presença, ausência, quantidade e localização dos segmentos cromossômicos. Além do método de cultura de linfócitos periféricos e analise molecular de sangue por PCR (Reação em Cadeia da Polimerase) e histopatológico (Bugno et al., 2008; Coppola et al., 2007).

\section{Relato de caso clínico}

Foi atendido uma fêmea bovina, raça mestiça (Holandesa X Abeerden Angus (Figura 1), $260 \mathrm{~kg}$ peso vivo, criado em sistema extensivo, em uma propriedade rural no Distrito Maratá no município de São Domingos, Santa Catarina.

$\mathrm{Na}$ anamnese, o produtor relatou que o animal apresentava alterações físicas, observadas durante o desenvolvimento. $\mathrm{O}$ mesmo apresentava saco escrotal com aspecto edemaciado, além de demonstrar dificuldade de locomoção, permanecendo na maior parte do tempo em decúbito. Relatou também, que 
o animal urinava invertido, em forma de jatos direcionados para o ânus, observado logo após seu nascimento até o décimo quarto mês de idade.

No exame físico e clínico, evidenciou-se alterações cardiorrespiratórias, apresentando frequência respiratória elevada, 52 movimentos respiratórios por minuto, sem presença de estertores. Na ausculta cardíaca, batimentos limpos sem presença de sopro, com frequência alterada para 120 batimentos por minutos. Os movimentos ruminais apresentavam-se normais e temperatura retal normal $38,5^{\circ} \mathrm{C}$. Turgor cutâneo e mucosas normais para a espécie. O paciente apresentava estrutura corporal de um bovino fêmea (Figura 2); porém, apresentava saco escrotal sendo que ao palpá-lo percebeu-se a presença de dois testículos (Figura 3), sendo o esquerdo de maior tamanho, consistência firme e imóvel e o direito de tamanho menor. Evidenciou-se também a presença do músculo cremaster e ao palpar o testículo o bovino realizava a tração ventral do mesmo. Na região cranial do saco escrotal, havia presença de um par de tetos disfuncionais e atrofiados (Figura 4).

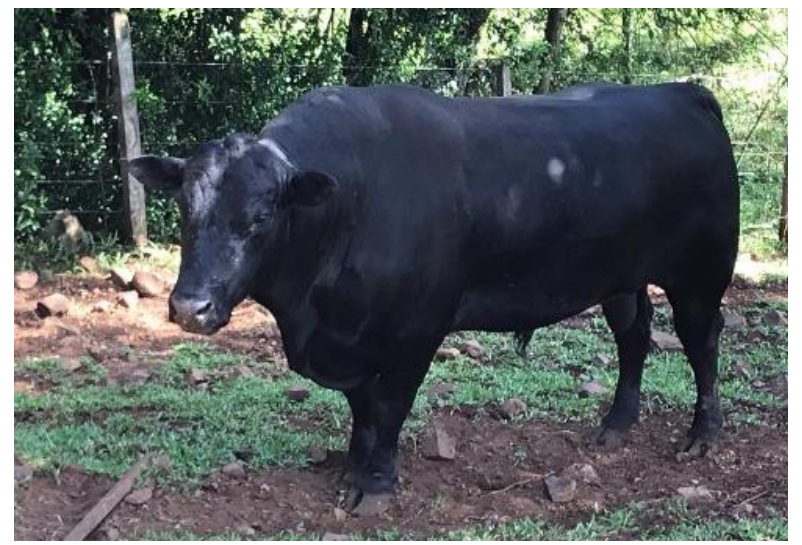

Figura 1. Touro raça Abeerden Angus, pai do bovino.

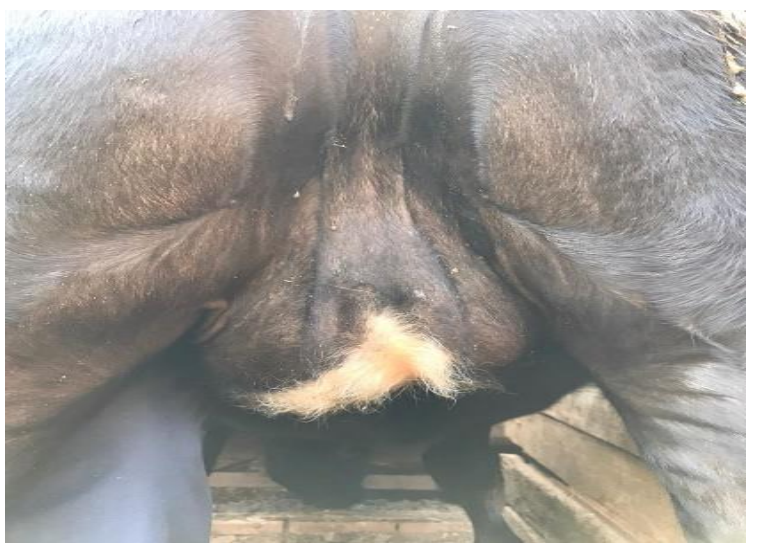

Figura 3. Presença de saco escrotal.

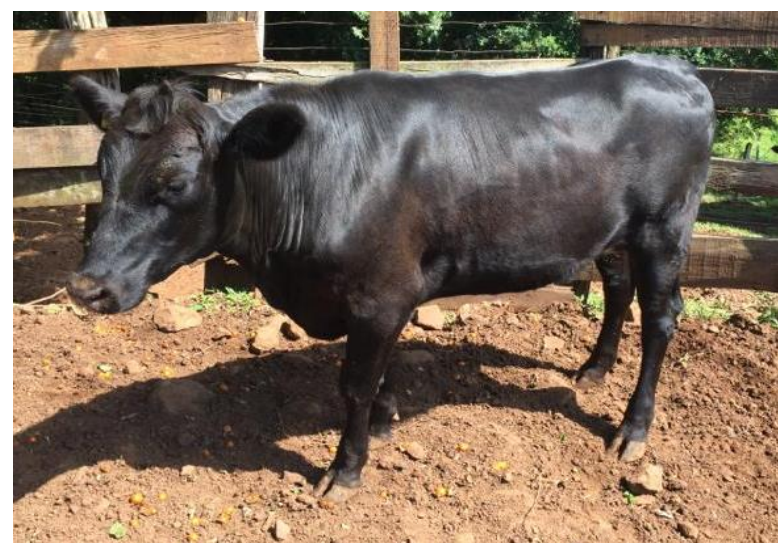

Figura 2. Bovino com estrutural corporal fêmea.

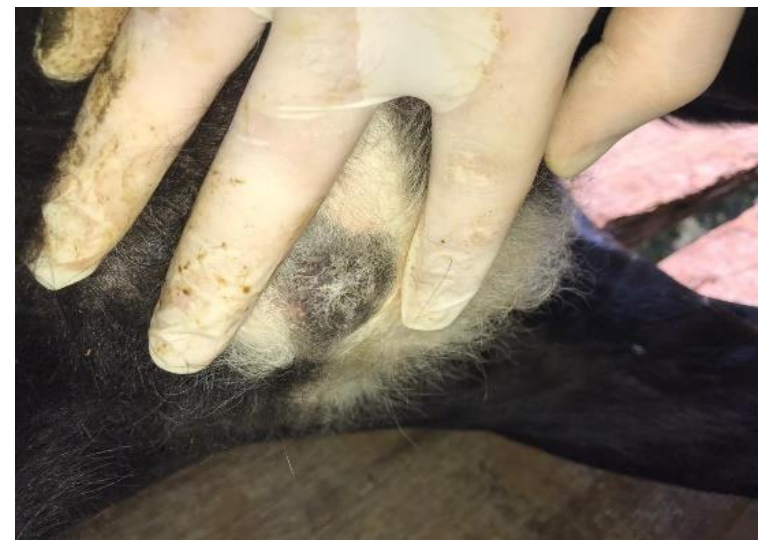

Figura 4. Presença de um par de tetos disfuncionais e atrofiados.

Foi identificado que o animal apresentava uma estrutura semelhante a glande localizado na parte interna da vulva (Figura 5), sendo que este bovino apresentava somente a vulva, sem vagina. Pela localização anatômica da glande, esta contribuía para que o paciente realizasse micção em foram de jatos, pois a mesma obstruía parcialmente a saída, fazendo que a urina fosse ejetava para região dorsal do animal (Figura 6).

Ao ser submetido a ultrassonografia via trans retal, identificou-se a presença do ovário esquerdo atrofiado e a ausência do direito (Figura 7A), além de um resquício de cérvix também atrofiado (Figura 7B). A vesícula urinária apresentava-se repleta e sem alterações (Figura 8).

Considerando as alterações encontradas no exame físico e nos exames ultrassonográficos o diagnóstico para o paciente foi um caso de hermafroditismo verdadeiro. Diante do diagnóstico, as recomendações ao produtor, foram o envio do animal para a engorda e posteriormente abate, pois mesmo com tratamento, não seria possível transformar funcional a parte de reprodução do paciente. 


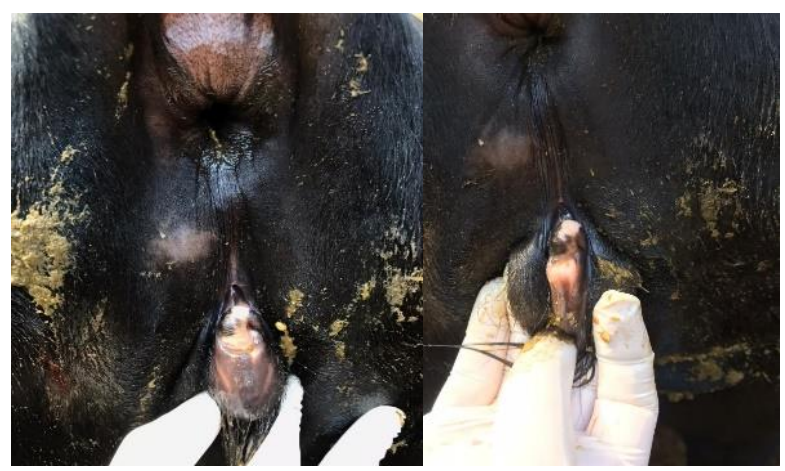

Figura 5. Glande atrofiada localizada na vulva da paciente.

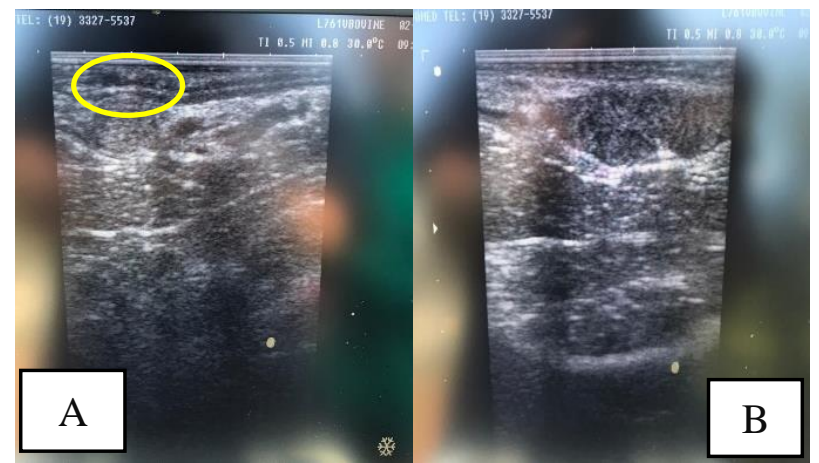

Figura 7. A) Ultrassonografia do ovário esquerdo atrofiado. B) Ultrassonografia do resquício de cérvix.

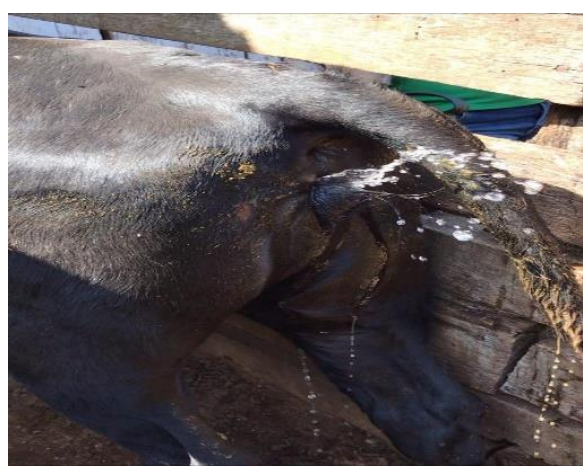

Figura 6. Urina sendo ejetada.

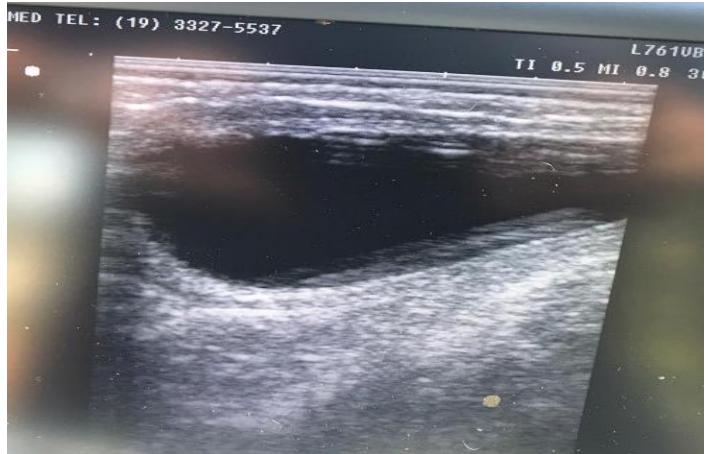

Figura 8. Ultrassonografia da vesícula urinaria.

\section{Discussão}

Em casos de intersexualidades, para chegar ao diagnóstico correto, inicialmente, são descartados os diagnósticos diferenciais, no caso abordado, pela minuciosa inspeção da paciente, associando, histórico, anamnese e o exame ultrassonográfico, descartou-se a anomalia Freemartinismo, que é muito comum principalmente em bovinos nascido de parto gemelar, que não foi o caso da paciente abordada. Em gestações gemelares heterossexuais, devido a anastomose vascular coriônica nas placentas dos fetos, entre 30 a 40 dias da gestação, geram dimorfismo sexual e em consequência, há uma circulação fetal comum de células (quimerismo hematopoiético) e substâncias plasmáticas (Ayala et al., 2000). O sangue de ambos os fetos, são misturados por aproximadamente 280 dias de gestação (Niku et al., 2007), promovendo o intercâmbio de hormônios, células sanguíneas e também o fator de diferenciação sexual entre os gêmeos. O fator inibidor de Müller (MIF), hormônio produzido pelas células de Sertoli, juntamente com a testosterona produzida pelas células de Leydig dos testículos (Brace et al., 2008), sejam os principais responsáveis pela formação da anomalia. Logo nos estágios iniciais do desenvolvimento nos mamíferos, os fetos apresentam dois pares de ductos: mesonéfricos (Wolff) e os paremesonéfricos (Müller). No macho, sobre a influência de andrógenos testiculares, os ductos de Wolff se desenvolvem em epidídimo, vasos deferentes e vesícula seminal. Nas fêmeas, os ductos de Müller desenvolvem o útero, as tubas uterinas, da cérvix e da vagina anterior (Rey et al., 2003). O MIF produzido pelos testículos do macho bloqueiam o desenvolvimento dos ductos de Müller na fêmea em gestações gemelares heterossexuais (Cabianca et al., 2007), gerando as anomalias no trato reprodutivo. Além disso, as gônadas do indivíduo masculinizado, produzem MIF em alguns casos, mantendo as altas concentrações do hormônio no plasma sanguíneo (Rota et al., 2002). A fêmea nascida de parto gemelar com essas características, possui genótipo feminino; porém, masculinizada pelos hormônios do macho no útero durante a determinação sexual, apresenta alterações nas estruturas reprodutivas (Padula, 2005). $\mathrm{Na}$ porção externa da vagina observa-se a presença de clitóris hipertrofiado, vulva pequena, pelos vulvares longos e grosseiros. Nos casos de Freemartinismo, a vagina apresenta-se curta com cerca de cinco centímetros de comprimento e com fundo cego e esterilidade. Na paciente, foi evidenciado presença somente da vulva, sem vagina e pênis dentro da vulva. $\mathrm{Na}$ avaliação uterina de pacientes com Freemartinismo, observa-se aspecto rudimentar, ausência de colo e cérvix uterina (Esteves et al., 2012), 
vestígios de gônadas masculinas e hipoplasia dos ductos de Müller (Brace et al., 2008). Glândulas vesiculares hipoplásicas e rudimentares são características marcantes dessa síndrome. A presença de testículos é rara nos animais acometidos pelo freemartinismo, somente nos casos de extrema influência de hormônios masculinizante, os testículos podem ser encontrados na região inguinal e no abdômen em posição ovariana (Peretti et al., 2008). Outra característica marcante nos pacientes acometidos por freemartinismo é a redução da distância entre o ânus e a vulva, ocasionando maior angulação na área vulvar (Esteves et al., 2012). Os sinais clínicos na fase adulta do animal, iniciam com histórico de falha reprodutiva, ausência de comportamento estral ou falha na concepção na presença do macho (Padula, 2005). Devido aos níveis altos de testosterona, as fêmeas tornando-se masculinizadas com maior desenvolvimento das porções craniais do organismo, tornando o pescoço curto e grosso, cabeça pesada e tórax mais desenvolvido, bom estado de carne, com maior massa muscular e acúmulo de gordura (Grunert et al., 2005). Os machos possuem maior peso de carcaça quente quando comparados a fêmeas, justificado pela maior taxa anabólica desse sexo (Philippe et al., 2020), além de o escore de marmoreio e qualidade das carcaças serem superiores a de fêmeas normais (Gregory et al., 1996), sendo descartados de rebanhos destinados a reprodução, pois são inférteis e não adequados à produção de leite (Esteves et al., 2012).

A paciente apresentou saco escrotal com presença de testículos e pelo exame de ultrassonografia evidenciou a presença dos ovários, estando um atrofiado, confirmando o diagnóstico de hermafrodita verdadeiro, que são caracterizados justamente pela presença de dois tipos de tecido reprodutivo, tecido testicular e ovariano (masculino e feminino), que podem estar em uma única gônada (ovotestis) e em gônadas separadas, simultâneos no mesmo animal, diferindo dos casos de Freemartinismo. Geralmente o tecido testicular é destituído de células germinativas, sendo que os ovários podem ter folículos normais e gerar descendentes. Os animais acometidos apresentam variados graus de ambiguidade genital, que aparecem durante a puberdade e na vida adulta, sendo em sua maioria, vias genitais externas femininas, com vulva rudimentar e clitóris hipertrofiado ( $\mathrm{Hafez} \& \mathrm{Hafez}, 2004)$. A teoria mais aceita tanto para hermafroditas verdadeiros quanto para pseudo-hermafroditas é que a anomalia seja causada devido a translocação do gene SRY para o cromossomo X, promovendo desenvolvimento testicular em indivíduos XX. E também que existam genes para o desenvolvimento testicular presentes no cromossomo X, que normalmente permanecem inativados (Campbell, 2004).

Pseudo-hermafroditismo masculino é mais recorrente, se comparado ao pseudo-hermafroditismo feminino e hermafroditismo verdadeiro (Steenholdt, 2007), principalmente nas espécies de bovinos, caprinos e suínos (Basrur \& Basrur, 2004; Bugno et al., 2008). No momento em que ocorre a formação do embrião na vida intrauterina, tem se presença das gônadas dos dois sexos, ocasionando em uma diferenciação anormal das genitálias externas e internas. Em pseudo-hermafroditas machos podem estar presentes os cromossomos sexuais XY ou XX e ainda com uma diferença do $\mathrm{Y}$, assim os ductos genitais e a genitália demonstram características femininas, divergindo de hipoplasia quando os casos são graves e até mesmo uma feminilização (Zenteno-Ruiz et al., 2001). Na maioria dos casos, apresentam a genitália externa feminina. O paciente pseudo-hermafrodita possui gônadas consistentes com o sexo cromossômico e a genitália externa do sexo oposto (Katz \& McDonald, 1992), o que não foi o caso da paciente abordado. Em casos de pseudo-hermafrodita feminino, tem-se a presença de ovários funcionais, no entanto as características físicas masculinas e genitália externa masculina. Já pacientes pseudohermafroditas masculinos, possuem testículos com masculinização incompleta, a genitália externa é feminina. Não tem formação do epidídimo, dos ductos deferentes e vesícula seminal, e à ausência de hormônios andrógenos, geram a falha na formação vaginal, cervical e uterina (Katz \& McDonald, 1992).

Três formas de pseudo-hermafroditas machos foram descritas, sendo a síndrome da persistência do ducto de Muller, relatada como hereditária adquirida, os animais possuem cromossomos XY ou XXY, são machos normais exceto em criptorquidas unilateral ou bilateral, estando os testículos aderidos aos cornos uterinos. Deficiência de $5 \alpha$-reductase, onde a falta de diidrotestosterona faz com que as estruturas que seriam masculinas se tornem femininas de forma passiva, sendo os animais afetados prováveis criptorquios. E a feminilização testicular, onde os pacientes machos apresentam testículos retidos na cavidade abdominal, produzindo fatores inibitórios dos ductos de Muller (MIF), atuando na produção de testosterona, não ocorrendo estímulo do sistema de Wolf devido a deficiência qualitativa e quantitativa de receptores de citosol para a união com o andrógeno, sucedendo em animal com genitália externa de fêmea, 
sem a presença de ductos de Muller e Wolf. As raças e espécies mais afetadas estão relacionadas ao alto grau de cruzamentos consanguíneos, por escolha ou falta de machos reprodutores (López et al., 2015).

Em relação a abordagem terapêutica, podem ser realizados tratamentos clínicos medicamentoso com a reposição hormonal e cirúrgico, corrigindo a genitália interna e externa, dependendo da opção do sexo de criação e do caso do paciente. Tendo em vista que a paciente abordada, se apresentava em um quadro de esterilidade o tratamento seria ineficaz pois o quadro do bovino era irreversível, foi recomendado que o proprietário, enviasse paciente para o descarte, visando a diminuição das perdas econômicas.

\section{Conclusão}

Os sinais clínicos que a paciente apresentou, foram de encontro com os casos relatados de hermafroditismo verdadeiro. Embora as anomalias congênitas de intersexualidade relacionadas ao aparelho reprodutor, estejam ligadas principalmente a animais que apresentem alto grau de parentesco, ou gestação gemelar, não se tratando do caso da paciente abordado, a recomendação de engorda e descarte do animal, contribui para que se tenha a diminuição do índice de nascimento de animais com a anomalia no rebanho do produtor e perdas econômicas ao proprietário.

\section{Referências bibliográficas}

Almeida, J. M. (1999). Embriologia veterinária comparada. Gunabara Koogan.

Ayala, V. M. Á., Villagómez, D. A. F., \& Benítez, S. L. S. (2000). Estudio citogenético y anatomopatológico del síndrome freemartin en bovinos (Bos taurus). Veterinaria México, 31(4), 313-320. https://doi.org/10.22201/fmvz.24486760e.2000.4.25.

Basrur, P. K., \& Basrur, V. R. (2004). Genes in genital malformations and male reproductive health. Animal Reproduction, 1(1), 64-85.

Basrur, P. K., \& Stranzinger, G. (2008). Veterinary cytogenetics: past and perspective. Cytogenetic and Genome Research, 120(1-2), 11-25. https://doi.org/10.1159/000118737.

Brace, M. D., Peters, O., Menzies, P., King, W. A., \& Nino-Soto, M. I. (2008). Sex chromosome chimerism and the freemartin syndrome in Rideau Arcott sheep. Cytogenetic and Genome Research, 120(1-2), 132-139. https://doi.org/10.1159/000118752.

Bugno, M., Ząbek, T., Golonka, P., Pieńkowska-Schelling, A., Schelling, C., \& Słota, E. (2008). A case of an intersex horse with 63, X/64, XX/65, XX, del (Y)(q?) karyotype. Cytogenetic and Genome Research, 120(1-2), 123-126. https://doi.org/10.1159/000118750.

Cabianca, G., Rota, A., Cozzi, B., \& Ballarin, C. (2007). Expression of AMH in female fetal intersex gonads in the bovine. Anatomia, Histologia, Embryologia, 36(1), 24-26. https://doi.org/10.1111/j.1439-0264.2006.00713.x.

Campbell, M. (2004). A case of male pseudohermaphroditism in a horse: Senior seminar paper. In Cornell University College of Veterinary Medicine (pp. 1-10). Ithaca, New York, USA.

Chauffaille, M. L. F. (2005). Citogenética e biologia molecular em leucemia linfocítica crônica. Revista Brasileira de Hematologia e Hemoterapia, 27, 247-252. https://doi.org/10.1590/s151684842005000400006.

Coppola, G., Alexander, B., Di Berardino, D., St John, E., Basrur, P. K., \& King, W. A. (2007). Use of cross-species in-situ hybridization (ZOO-FISH) to asses chromosome abnormalities in day-6 invivo- or in-vitro-produced sheep embryos. Chromosome Research, 15(3), 399-408. https://doi.org/10.1007/s10577-007-1125-2.

Esteves, A., Båge, R., \& Payan-Carreira, R. (2012). Freemartinism in cattle, ruminants: Anatomy, behavior and diseases. Nova Science Publishers Inc.

Fernández, M. F., Olmos, B., \& Olea, N. (2007). Exposición a disruptores endocrinos y alteraciones del tracto urogenital masculino (criptorquidia e hipospadias). Gaceta Sanitaria, 21(6), 500-514. https://doi.org/10.1157/13112246.

Gregory, K. E., Echternkamp, S. E., \& Cundiff, L. V. (1996). Effects of twinning on dystocia, calf survival, calf growth, carcass traits, and cow productivity. Journal of Animal Science, 74(6), 1223 1233. https://doi.org/10.2527/1996.7461223x. 
Grunert, E., Birgel, E. H., \& Vale, W. G. (2005). Patologia e clínica da reprodução dos animais mamíferos domésticos: ginecologia. Varela.

Hafez, B., \& Hafez, E. S. E. (2004). Reprodução Animal (Vol. 1, p. 513). Manole: São Paulo, Brasil.

Howden, K. J. (2004). Androgen insensitivity syndrome in a thoroughbred mare (64, XY-testicular feminization). The Canadian Veterinary Journal, 45(6), 501-503.

Katz, L. S., \& McDonald, T. J. (1992). Sexual behavior of farm animals. Theriogenology, 38(2), 239253. https://doi.org/http://dx.doi.org/10.1016/0093-691X(92)90233-H

López, F. J. P., Dibbern, L. S., Chávari, A. C. T., Homero, S. G., Ramos, A. A., \& Nájera, M. J. F. (2015). Intersexualidade em caprinos. Revista Electrónica de Veterinaria, 16(6), 1-13.

Nascimento, E. F., \& Santos, R. L. (2000). Patologia da reprodução dos animais domésticos. Grupo Gen-Guanabara Koogan.

Niku, M., Pessa-Morikawa, T., Taponen, J., \& Iivanainen, A. (2007). Direct observation of hematopoietic progenitor chimerism in fetal freemartin cattle. BMC Veterinary Research, 3(1), 1-5. https://doi.org/10.1186/1746-6148-3-29.

Padula, A. M. (2005). The freemartin syndrome: an update. Animal Reproduction Science, 87(1-2), 93109. https://doi.org/10.1016/j.anireprosci.2004.09.008.

Payan-Carreira, R., Pires, M. A., Quaresma, M., Chaves, R., Adega, F., Pinto, H. G., Colaço, B., \& Villar, V. (2008). A complex intersex condition in a Holstein calf. Animal Reproduction Science, 103(1-2), 154-163.

Peretti, V., Ciotola, F., Albarella, S., Paciello, O., Dario, C., Barbieri, V., \& Iannuzzi, L. (2008). XX/XY chimerism in cattle: clinical and cytogenetic studies. Sexual Development, 2(1), 24-30. https://doi.org/10.1159/000117716.

Philippe, M. G., Clementino, F. M. M., Gadotti, G. A., Puel, A. C., Martins, C. E. N., Moreira, F., Oliveira Júnior, J. M., \& Peripolli, V. (2020). Características da carcaça e da carne de bovinos de corte certificados. Brazilian Journal of Development, 6(7), 52942-52951. https://doi.org/10.34117/bjdv6n7-805.

Rey, R., Lukas-Croisier, C., Lasala, C., \& Bedecarrás, P. (2003). AMH/MIS: what we know already about the gene, the protein and its regulation. Molecular and Cellular Endocrinology, 211(1-2), 2131. https://doi.org/10.1016/j.mce.2003.09.007.

Rota, A., Ballarin, C., Vigier, B., Cozzi, B., \& Rey, R. (2002). Age dependent changes in plasma anti-Müllerian hormone concentrations in the bovine male, female, and freemartin from birth to puberty: relationship between testosterone production and influence on sex differentiation. General and Comparative Endocrinology, 129(1), 39-44. https://doi.org/10.1016/S0016-6480(02)00514-2.

Steenholdt, C. W. (2007). Infertility due to noninflammatory abnormalities of the tubular reproductive tract. In R. S. Youngquist \& W. R. Therelfall (Eds.), Current Therapy in Large Animal Theriogenology (pp. 383388). Elsevier. https://doi.org/10.1016/B978-072169323-1.50051-9.

Zenteno-Ruiz, J. C., Kofman-Alfaro, S., \& Méndez, J. P. (2001). 46, XX sex reversal. Archives of Medical Research, 32(6), 559-566. https://doi.org/10.1016/S0188-4409(01)00322-8.

Histórico do artigo:

Recebido: 8 de junho de 2021

Aprovado: 27 de julho de 2021
Licenciamento: Este artigo é publicado na modalidade Acesso Aberto sob a licença Creative Commons Atribuição 4.0 (CC-BY 4.0), a qual permite uso irrestrito, distribuição, reprodução em qualquer meio, desde que o autor e a fonte sejam devidamente creditados. 